position in further experiments would be of considerable interest.

Levine (1959) devised a statistic, the percentage variance explained (PVE), which is a check of the internal consistency of the model, which can vary from 0 to 1 . As seen in the last column of Table 1, these are quite respectable and, in general, are of the same order of magnitude as those Levine (1959) has reported for rhesus monkeys. The increasing magnitude of the PVE as acquisition proceeded is of interest. Levine's model assumes that the $S$ does not change hypotheses during the three trials analyzed within a given problem. Violations of this assumption can show up as third-trial learning (when the shift in strategy is to the correct hypothesis) or as random responding (when the shift is to an incorrect hypothesis). Furthermore, since such changes in hypotheses are violations of the model, they might be expected to lower the PVE. The correlation of decreases in the probabilities of random responding and third-trial learning with an increase in the PVE suggests that changes in hypotheses do take place during Trials 1-3.

The meaningful patterns found in the results of the hypothesis analysis, as well as the reasonably high PVEs, clearly suggest that the hypothesis model is applicable to the learning-set behavior in bluejays. Certainly, the evidence obtained in mynas and bluejays suggest that a theoretical model, in terms of response patterns, rather than discrete trial-by-trial choice response, will be most appropriate. Further research designed to test this position is clearly necessary. Examples would include tests of transfer from reversal learning to learning set, attempts to shape other strategies, such as the win-shift/lose-stay position, by appropriate contingencies, or studies of short-term memory in learning-set experienced birds. Such research might well confirm the utility of the hypothesis or response strategy model for the learning process during learning set in corvids, as it seems to have done in macaque monkeys. If so, it will provide evidence for the parallel and independent development of similar modes of capability for behavioral modification in organisms differen in nervous system structure and habitai.

\section{REFERENCES}

BEHAR, I. Analysis of object-discrimination learning in rhesus monkeys. Journal of Comparative \& Physiological Psychology, $1961,54,539-542$.

BESSEMER, D. Retention of object discrimination in learning-set experienced monkeys. Unpublished doctoral dissertation, University of Wisconsin, 1966 .
HARLOW, H. F. Learning set and error factor theory. In $S$. Koch (Ed.), Psychology: A study of a science. Vol. 2. New York: McGraw-Hill, 1959 Pp. 492-537.

KAMIL, A. C, \& HUNTER, M. W., III. Performance on object discrimination learning-set by the Greater Hill Myna (Gracula Religiosa). Journal of Comparative \& Physiological Psychology, in press.

LEVINE, M. A model of hypothesis behavior in discrimination learning-sets. Psychological Review, 1959, 66, 353-366.

LEVINE, M. Hypothesis behavior. In A. M. Schrier, H. F. Harlow, and F. Stollnitz (Eds.), Behquior of nonhuman primates: Modern research trends. Vol.1. New York: Academic Press, 1965. Pp. 97-127.

MILES, R. C. Learning-set formation in the squirrel monkey. Journal of Comparative \& Physiological Psychology, 1957, 50, 356-357.
MILES, R. C., \& MEYER, D. R. Learning sets in marmosets. Journal of Comparative \& Physiological Psychology, 1956, 49, 219-222.

SCHUSTERMAN, R. J. Successive discrimination-reversal training and multiple discrimination training in one-trial learning by chimpanzees. Journal of Comparative \& Physiological Psy chology, 1964, 58, 153-156.

WARREN, J. M. Primate learning in comparative perspective. In A. M. Schrier, H. F. Harlow, and F. Stollnitz (Eds.) Behavior of nonhuman primates: Modern research trends. Vol. 1 . New York: Academic Press, 1965. Pp. 249-281.

WARREN, J. M. Reversal learning and the formation of learning sets by cats and monkeys. Journal of Comparative \& Physiological Psychology, 1966, 61, 421-428.

\title{
Spontaneous alternation of brightness?
}

\author{
R. O'CONNELL \\ San Fernando Valley State College, Northridge, Calif. 91324
}

An attempt is made to dispel misunderstanding regarding a study which found spontaneous alternation to be affected by stimulus change but not by any tendency to alternate brightness. It is urged that the distinction between response to change and the alternation of brightness not be lost. Positive evidence for the alternation of brightness is presented.

Pate \& DeLoache (1970) stated that several investigators (Glanzer, 1953; O'Connell, 1964; Walker, Dember, Earl, \& Karoly, 1955) claimed to have found spontaneous alternation of visual stimuli. This is one-third incorrect. Glanzer, who separated alternation of relative turn from alternation due to other factors, used one black arm and one white arm; but this visual difference, and any other visual differences between the arms, were confounded with differences in spatial location in the room (absolute direction of turn) and odor. Walker et al still found alternation of brightness when the confounding with place (absolute turn) was eliminated, but the confounding with odor cues remained.

O'Connell used a design in which brightness difference between the arms was not confounded with any of the other cues and found no evidence that alternation to the combination of other cues was influenced by a brightness alternation tendency. This study used a stationary T-maze to examine both spontaneous alternation and the response to stimulus change. "Response to stimulus change" refers to the tendency to select an arm which has been changed (or changed most) between a first, exposure trial and a second, choice trial (Dember, 1956). The term "stimulus change" can and has been used to refer to various events, but the specific event here intended is the temporal change in a stimulus which has been associated with a particular location. In addition to stimulus change, the study independently investigated the possibility that alternation might be increased if the Trial 2 brightness of the arm unentered on Trial 1 was different from the brightness of the arm entered on Trial 1 . Note that the phenomenon of brightness alternation is defined in terms of operations which differ from those used to demonstrate the response to change, though in both cases one is, in some sense, investigating approach to a novel 
stimulus. Position preferences made it impossible to deal adequately with brightness preference so as to assess well any tendency to alternate brightness. However, none of the four comparisons to test for brightness alternation was significant, and on the last 4 of the 8 experimental days, three of the four brightness conditions resulted in exactly the same percentage of alternation as their comparison conditions. These results, contained in the original report, apparently did not come through clearly.

Quite possibly the misunderstanding arose from the fact that the study contained the conclusion: "The results show that alternation is influenced by a brightness change in one of the choice arms." This effect of a change in one arm from Trial 1 to Trial 2 is the stimulus-change effect. No effect was reported as a function of whether the Trial 2 brightness of the arm unentered on Trial 1 was the same as or different from the brightness of the arm entered on Trial 1: the brightness alternation effect.

The distinction between these two procedures was also somewhat blurred in a study by Franken \& Baker (1967). They investigated the effect of temporal stimulus change under different levels of deprivation. However, when their stimuli differed in brightness, brightness alternation and response to stimulus change were confounded. They stated that their results failed to substantiate Douglas's (1966) conclusion that "stimulus change is relatively unimportant in accounting for spontaneous alternation [Franken \& Baker, 1967, p. 89]." However, Douglas investigated the role of a brightness difference between the arms on alternation; he did not deal with the response to stimulus change, as here defined. In a later study, Franken \& Baker (1969) again manipulated stimulus change and drew conclusions about the role of visual cues in spontaneous alternation. This is not incorrect, but it must be remembered that the test procedure for spontaneous alternation does not necessarily involve any change in the stimulus which has been in a particular location. The stimulus-change procedure may be combined with the spontaneous-alternation procedure, and, when this is done, one finds stimulus change does have an effect (O'Connell, 1964); however, this does not allow one to draw conclusions regarding the effect of brightness difference or other visual cues on alternation when stimulus change is not produced.

Only two studies provide any positive evidence for spontaneous alternation of brightness. Thompson (1960) used a + maze which, in one condition, was unrotated between trials, so that the same $T$ was used on both trials. Absolute turn, relative turn, and odor were, therefore, available as cues. In this condition, whether the arms were both black or one black and one white made little difference; only one of four comparisons differed by more than $1 \%$. This result is in agreement with other results obtained under rather comparable conditions (e.g., Dember \& Roberts, 1958; O'Connell, 1964; Thompson, 1962; Thompson \& Thompson, 1964; Walker, unpublished manuscript cited in Dember \& Fowler, 1958 ). When the maze was rotated between trials, Trial 2 started from a relatively odor-free start stem (see Still \& MacMillan, 1969, on the importance of odor as a contextual cue apart from any tendency to select an arm free of odor trail), and, though odor cues were available in the arms, they were opposed to cues of absolute and relative turn. Under these rotated-maze conditions, if one considers just the Ss that were not rewarded for their responses, with both arms black, turn alternation was at $65 \%$; with one arm white and one black, turn alternation was at $40 \%$ and brightness alternation at $60 \%$ (determined from raw data supplied by Thompson). This $25 \%$ difference in turn alternation is not significant if evaluated with the number of $S s$ in each group $(N=20)$, but, if the 12 tests are treated as yielding independent measures for these $\mathrm{Ss}-$ for which there is some justification (Douglas, 1966)-the difference is significant $(p<.01)$ for these Ss.

The second study, by Eisenberger, Myers, Sanders, \& Shanab (1970), controlled for relative turn and removed odor and absolute turn as alternation possibilities. The arms were black and white, and alternation of arm brightness differed significantly from what was determined to be chance level of alternation. They did not use a comparison condition with arms of equal brightness. These authors noted reasons which might account for the difference between their positive results and the negative findings of Douglas (1966). An additional factor which may be of importance is the greater difference between the mazes used on the two trials by Douglas.

An additional study (Pate \& Anders, 1967), which did not use the traditional alternation procedure but exposed Ss to a brightness in the startbox prior to one-choice trial, found a tendency to select the nonexposure brightness for male rats only. An attempt at replication was not successful (Lester, i968). Such exposure studies seem to be complicated by changes in S's relative aversion to white (Pate, 1967), changes in brightness preference which may have more to do with anxiety than any preference for the new.

It appears, then, that there is some evidence for brightness alternation when the effects of odor and absolute turn cues are attenuated but when the context is not greatly modified between trials.

\section{REFERENCES}

DEMBER, $W$. N. Response by the rat to environmental change. Journal of Comparative \& Physiological Psychology. $1956,49,93-95$.

DEMBER, W. N. \& FOWLER, H. Spontaneous alternation behavior. Psychological Bulletin, 1958, 55 $412-428$.

DEMBER, W. N., \& ROBERTS, W Alternation behavior in peripherally blinded rats. Perceptual \& Motor Skills, $1958,8,91-94$.

DOUGLAS, R. J. Cues for spontaneous alternation. Journal of Comparative \& Physiological Psychology, 1966, 62, 171-183.

EISENBERGER, R., MYERS, A. K. SANDERS, R., \& SHANAB, M. E. Stimulus control of spontaneous alternation. Journal of Comparative \& Physiological Psychology, 1970, 70 , 136-140.

FRANKEN, R. E., \& BAKER, J. G. Drive level and cue utilization in spontaneous alternation. Psychonomic Science, 1967. 8, 89-90.

FRANKEN, R. E., \& BAKER, J. G. The effects of drive level on cues utilized in spontaneous alternation. Psychonomic Science, 1969, 16, 239-240.

GLANZER, $M$. The role of stimulus satiation in spontaneous alternation. Journal of Experimental Psychology, $1953,45,387-393$.

LESTER, D. Pre-exposure and stimulus choice: Effects of locale. Psychonomic Science, $1968,12,3-4$.

O'CONNELL, R. H. Comparison of alternation and response to stimulus change. Journal of Comparative \& Physiological Psychology, 1964, 57, $362-366$.

PATE, J. L. Choice behavior as a function of stimulus exposure. Psychological Reports, 1967, 21,213-219.

PATE, J. L., \& ANDERS, T. R. Extra-maze pre-exposure and choice behavior. Psychonomic Science, 1967, 7, 301-302.

PATE, J. L. \& DeLOACHE, J. Brightness and direction as cues for spontaneous alternation behavior. Psychonomic Science, $1970,18,27-28$.

STILL, A., \& MacMILLAN, A. Odor trail and spontaneous alternation. Psychonomic Science, 1969, 16, 160-161. THOMPSON, M. E. Alternation in a t maze as a function of three variables. Psychological Reports, 1960, 7, 103-110.

THOMPSON, M. E. Stimulus alternation, response repetition, and response alternation in a multiple-choice situation. Psychological Reports, 1962. 11, 523-527.

THOMPSON, M. E., \& THOMPSON. J. P. Alternation and repetition in a multiple-choice situation. Psychological Reports, 1964, 14, 505-506.

WALKER, E. L.. DEMBER, w. N., EARL, R. W., \& KAROLY, A. J. Choice alternation: I. Stimulus vs place vs response. Journal of Comparative \& Physiological Psychology, 1955, 48, 19-23. 